\title{
PROBLEMAS FISCALES Y DE ENSEÑANZA EN LEÓN DURANTE EL REINADO DE CARLOS IV (1793-1805)
}

\author{
JuAN MANUEl BARTOLOMÉ BARTOLOMÉ \\ Universidad de León
}

Fecha de recepción: diciembre de 2009

Fecha de aceptación: febrero de 2010

\section{INTRODUCCIÓN}

El reinado de Carlos IV resulta muy atractivo no sólo por el conjunto de dificultades generadas por la evolución de las estructuras (económicas, sociales, políticas) y las consecuencias de todo orden de la Revolución, sino también por su contribución al desmoronamiento del edificio entero del Antiguo Régimen y por la positiva aceleración intelectual de los últimos años del siglo XVIII y los primeros del XIX ${ }^{1}$.

En la provincia de León, a pesar de la relevancia de dichos años, son muy escasos los estudios que se han centrado en dicho periodo, predominando la temática de la desamortización, la denominada de Godoy² .

De ahí, que tomando como base fundamental la documentación del archivo municipal de León, del catastro del marqués de la Ensenada y particularmente la de protocolos notariales, en este trabajo nos proponemos abordar dos aspectos, que a priori pueden resultar inconexos: hacendísticos y educativos, pero ya veremos que guardarán una mayor relación de la esperada, debido fundamentalmente a que los problemas

1. Molas Ribalta, Pere: «Preámbulo», en La España de Carlos IV ( Pere Molas Ribalta editor), Madrid, 1991, p.10.

2. LORENZANA FERNÁNDEZ, Antonio, «Desamortización y transferencia de propiedad inmobiliaria en la ciudad de León a principios del siglo XIX», en Revista Estudios Humanísticos», N 19, León, 1997.

RUBIO PÉREZ, Laureano, « Los bienes de las cofradías y su desamortización durante el reinado de Carlos IV: un primer proceso de centralización de la tierra en la diócesis de Astorga», en Tierras de León, $N^{\circ} 66$, 1987, pp.47-57.

Aguado Cabezas, Elena, «La desamortización de Godoy», en La desamortización de Mendizabal y Espartero en la provincia de León (1836-1851), León 2.002, pp. 77-87. 
hacendísticos, fiscales, y en definitiva económicos, incidían en los educativos y de enseñanza .

De este modo, los objetivos planteados son: por una parte, tratar de dar respuesta a la incidencia de los problemas de la hacienda nacional en la fiscalidad provincial, y sobre todo en los bienes de propios de los municipios y en las obras pías, orientadas a cubrir las necesidades, entre ellas la enseñanza, de los más desfavorecidos. Y, por otra, analizar los problemas educativos, de enseñanza, en la ciudad de León y cuáles fueron las medidas que se adoptaron intentando buscar su solución.

\section{LOS EFECTOS NEGATIVOS DE LA CRISIS DE LA HACIENDA EN LOS BIENES MUNICIPALES Y EN LA ENSEÑANZA}

Donde peor se encontraban las cosas en el reinado de Carlos IV eran en las arcas del Estado ${ }^{3}$. No vamos a profundizar en este tema tan complejo de la crisis de la hacienda española durante estos años y tan bien analizado ${ }^{4}$; tampoco nos vamos a detener en el estudio ya clásico de las desamortizaciones, aunque somos conscientes que queda todavía mucho por investigar en la provincia de León ${ }^{5}$, sino que nuestra atención se va a centrar en averiguar la incidencia que tuvieron ciertas medidas fiscales, conectadas con la crisis de la hacienda nacional, en las propiedades de los municipios, en concreto de los bienes de propios, y en el ámbito de la atención a la población más desprotegida, huérfanas, y a su enseñanza. Nos estamos refiriendo, en concreto, a la que se conoce como «Renta del Tabaco», de 1793; a la Real Cédula de 1798 y al subsidio extraordinario de los 300 millones de 1800. De las tres mencionadas sólo la última, el subsidio extraordinario, es la más conocida ${ }^{6}$.

3. GONZÁLEZ ENCISO, Agustín, «La economía española en el reinado de Carlos IV», en La España de Carlos IV..., p. 32.

4. Artola, Miguel, La Hacienda del Antiguo Régimen, Madrid, 1982, pp. 321-445.

Merino, J.P., «La Hacienda de Carlos IV», en Hacienda Pública Española, 69, 1981.

GONZÁLEZ ENCISO, Agustín, «La economía española en el reinado de Carlos IV», en La España de Carlos IV, pp. 32-35.

GARCía GARCíA, Carmen, La Crisis de las Haciendas Locales, Valladolid, 1996

5. En realidad sólo se han realizado estudios, es el caso de Antonio Lorenzana Fernández, sobre la desamortización de propiedades inmobiliarias pertenecientes a instituciones radicadas en la ciudad de León, o sobre ventas de propiedades de cofradías en el obispado de Atorga, en concreto unas 147 hectáreas ubicadas en 26 pueblos, que es lo que ha analizado Laureano Rubio Pérez. En definitiva, reducidas muestras, pero que nos advierten de su significativa importancia cuantitativa y del alto interés por hacerse con este tipo de bienes, donde participaron un número alto de campesinos, seguramente llevadores de las fincas, individualmente o asociados, para no perder el control de las mismas y evitar la subida de las rentas. También es digno de destacar la venta de 207 viviendas en León ciudad sobre una población de unos 6.000 habitantes, según los datos del Censo de Floridablanca. AGUAdo CABEZAS, Elena, « La desamortización...», p. 87. PÉREZ GARCÍA, José Manuel, «Demografía leonesa en el Antiguo Régimen (1500-1850)», en Historia de León, V. III. Edad Moderna, León, 1999. pp. 188-196.

6. Sobre todo sus efectos negativos sobre las economías locales castellanas, Medina de Rioseco y Valladolid, donde se cubrieron los respectivos cupos asignados. GARCÍA GARCÍA, Carmen, La Crisis de las Haciendas... pp. 264-269. 
La denominada «Renta del Tabaco», tiene su origen en la Real Cédula del nueve de octubre de 1793, en la que se acuerda por parte de Carlos IV que debido a «... que es necesario atender a los elevados gastos del pasada guerra , la más costosa que ha tenido jamás la Monarquía...», los capitales a «...beneficio de Mayorazgos, Vínculos, Patronatos y Obras Pías...» ${ }^{8}$, pasen a la Real Hacienda como censos redimibles, pagándose el interés al tres por ciento, señalando como hipoteca especial para efectuar dichos pagos La Real Renta del Tabaco ${ }^{9}$. Tal medida ya se tomó anteriormente con Carlos III, en $1780^{10} \mathrm{y}$ las razones que se dan, en estos momentos, para que estos capitales se trasladen a la arcas estatales son de carácter liberal ${ }^{11}$.

Los encargados en la ciudad y provincia de descubrir los poseedores, apoderados o administradores de los beneficios señalados, son en primera instancia el intendente provincial $^{12}$. No obstante, ante la no presencia de algunos poseedores o administradores, el intendente va a nombrar al procurador síndico personero del común, para que ejerza de testigo de los capitales que son sacados y entregados a la tesorería ${ }^{13}$. Por lo tanto, el objetivo no era apropiarse el estado de bienes raíces, inmuebles urbanos o la amortización de vales reales, sino que lo que le interesaba eran los capitales contantes, monedas de oro, plata y vellón, sobre los cuales se establecía, como ya se ha señalado, un censo redimible con réditos de tres por ciento al año y cuya hipoteca eran la Renta del Tabaco, en concreto la paga de los réditos se sitúa en los rendimientos anuales de la referida Renta de Tabaco de la ciudad de León y su partido ${ }^{14}$. Es más, el propio Rey asegura las operaciones con « ...La Real palabra que tiene empeñada en la Real

7. Hace referencia al conflicto con Francia, que comienza en 1793, tras la ejecución de Luis XVI.

8. Archivo Histórico Provincial de León (A.H.P.L.), Félix González Mérida, Caja 862.

9. La renta del tabaco, según Agustín González Enciso, fue en ascenso, sobre todo desde 1795-97 y ,tras un bache desde 1800. Como la renta «estaba basada en el vicio», no importaba perjudicar a los presuntos consumidores con un aumento en el precio si se podía mantener la renta al alza, y eso es lo que se hizo. GONZÁLEZ ENCISO, Agustín, «La economía española ...», p. 33.

10. Tras haber entrado España en la Guerra de Independencia de Estados Unidos

11. «...mediante hallarse estos capitales sin circulación, los poseedores de Mayorazgos y Obras Pías careciendo de sus réditos, y el público de la circulación de estos fondos que existen como muertos en los depósitos, y expuestos a otras contingencias...», Félix González Mérida, Caja 862.

12. En el caso del León se trata de don Jacinto Lorenzana, intendente interino de dicha ciudad y su provincia. Ibidem.

13. El auto acordado en 1766, 5 de mayo, crea la figura de procurador sndico personero del público allí donde el oficio de procurador general estuviese enajenado en alguna familia o lo ejerciese un regidor. Sin embargo, en León la figura del procurador síndico general seguirá existiendo como tal junto a la del personero. CEBreiro Álvarez, E.., El municipio de Santiago de Compostela a finales del Antiguo régimen (1759-1812), Santiago de Compostela, 199, p. 236. GóMEZ MARTínEZ, Alfredo, «Cargos y oficios municipales en las ciudades de León, Zamora y Salamanca durante el reinado de Carlos III, en Revista Estudios Humanísticos, Historia, $\mathrm{N}^{\circ}$ 5, León, 2006, p. 175.

14. A.H.P.L, Félix González Mérida, Caja 862. 
Cédula inserta» y ,además, se establecen una serie de condiciones que tratan de dar seguridad, por lo menos en el papel, a los censualistas ${ }^{15}$.

En la ciudad y provincia de León la imposición de censos sobre capitales recibidos empezó en el año 1794 y tuvo una duración de unos once años, hasta $1805^{16}$. El total de capitales que se consiguieron recaudar para imponer a censos fue de 364.877 reales $^{17}$, siendo los años de mayor acopio los primeros, es decir, 1794, 1795, con 682.506 reales y 82.400 reales respectivamente y especialmente el año 1799 , con 155.601 reales, un $88,6 \%$ más respecto a los de 1794; sin embargo, dichas cifras hay que tomarlas con precaución ya que se deben en gran parte a las aportaciones que realizan las juntas de propios de la ciudad de León, y sobre todo de la villa de Astorga, provenientes de la venta de casa, debido al Real Decreto de 1798 que analizaremos posteriormente.

Ahora bien, más que las cantidades, que en ciertos años, sobre todo los primeros, fueron relevantes, nos interesa analizar la incidencia de dichos traspasos de capitales sobre el común de vecinos y particularmente en los más desfavorecidos, huérfanas, etc., que eran los que recibían la atención económica y educativa de las denominadas obras pías. Así, en un primer acercamiento cuantitativo, el dinero que paso a las tesorería del estado de las Obras Pías represento un porcentaje del 34,4\% en el año 1794, un 35,9\% en 1798 , un $80,4 \%$ en 1797 y un $100 \%$ en 1805 . Es decir, cantidades significativas que dejaban de disponer de ellas por un interés de tan sólo el 3\%, aunque también es cierto que parte de esos capitales que pasan al estado provenían también de censos, pero no todos ellos, como veremos posteriormente. Es más, si sólo nos fijamos en los capitales de las Obras Pías de estudiantes éstos suponen un 20,6\% en $1794^{18}$ y un $35,9 \%$ en $1798^{19}$. Por lo tanto, esta operación financiera, denominada «La Renta del Tabaco», fue más negativa que positiva a la hora de analizar sus consecuencias sobre las obras pías destinadas al ejercicio de la caridad hacia las huérfanas o a la enseñanza de sectores con escasos medios económicos, ya que sus capitales de fundación pasaron a manos de la hacienda estatal, a cambio de un bajo interés del 3\%. La única explicación favorable, sería, como ya hemos expuesto, que dichos capitales ya estaban situados en censos al

15. Es de destacar la segunda, donde se señala que en caso de retardación del pago de los réditos ha de poder el dueño o persona que delegue pedir ejecución en la Sala de Justicia del Consejo Real, Chancillerías y Audiencias más cercanas, contra los productos de la expresada Renta de Tabaco. Y también se establece que dichos productos no gocen ni puedan gozar de fuero o privilegio fiscal, para que no se impida la cobranza efectiva y pronta de los expresados réditos. Ibidem.

16. Ver cuadro 1.

17. Para poder apreciar mejor estas cantidades hay que señalar que a mediados del siglo XVIII se realizó en la ciudad de León el encabezamiento de las rentas provinciales del casco y la cantidad que se establece, tras una rebaja de 29.412 reales, es la de 365.342 reales. BARTOLOMÉ BARTOLOMÉ, Juan M., «De la administración particular a la gestión por el común de vecinos de la rentas provinciales de la ciudad de León en el siglo XVIII», en Revista Studia Histórica (en prensa).

18. En concreto, 17.000 reales son de la Obra Pía de estudiantes que había sido fundada en Villafranca del Bierzo por don Antonio de Faria y doña Isabel Rodríguez. A.H.P.L., Félix González Mérida, Caja 862,

19. La Obra Pía de estudiante pobres de Sobarriba, cuyo patrón es la Junta de Temporalidades de los bienes de los jesuitas, aporta 4.9850 reales. Id. Caja 865 . 
mismo tipo de interés, pero éstos sólo son el $26,1 \%$ y se correspondía más con los antiguos bienes de los jesuitas y administrados por la Junta de Temporalidades ${ }^{20}$

La Real Cédula de1798 establece que se vendan en pública subasta todas las casas que pertenecen y poseen los propios y arbitrios ante los problemas para su conservación y reparación ${ }^{21}$. Además, también se esgrimen de nuevo razones de carácter librecambista $^{22}$. De este modo, la junta de propios de León ${ }^{23}$ decide que se venda la única casa que tienen situada en la plaza de San Marcelo y junto al patio de comedias. Los bienes inmuebles de propios del ayuntamiento leonés eran muy escasos, ya que sus ingresos a mediados del siglo XVIII representaban únicamente el $2,1 \%{ }^{24}$ y en la cuentas de propios de 1751 sólo se hace referencia a tres casas arrendadas: dos en la plaza de la Regla y otra en San Marcelo ${ }^{25}$. De ahí, que no nos sorprenda la declaración de que se ponga en venta a finales del siglo XVIII la única casa disponible. Desde la publicación de la Real Cédula, el 21 de febrero, hasta la adjudicación de la venta de la casa, el treinta de agosto, pasaron un total de seis meses. Los pasos que se tomaron durante dicho tiempo fueron los siguientes: en marzo la junta municipal del propios y arbitrios nombran a dos peritos para que procedan a la tasación de la citada finca ${ }^{26}$, los cuales dado su estado deplorable la tasan en unos 16.537 reales $^{27}$. En abril se publicó la Real Cédula $^{28}$, y la subasta de la casa por dos veces. En mayo se procedió por parte del ayuntamiento $^{29}$ a la subasta a la cual sólo se presentó don Ramiro de Robles, canónigo de la catedral y administrador del Hospital de San Antonio Abad, el cual ofreció la cantidad de 13.780 reales y ante la ausencia de una nueva puja se le adjudicó en dicha

20. En la documentación se especifica si provienen de anteriores censos y los capitales de los mismos son un total de 95.336 reales.Id., Cajas 862 a la 870.

21. Debido a que en su «...conservación y reparación se gasta toda o la mayor parte de su producto que por lo regular no corresponde al capital y si se arruinan causan empeños insoportables a los mismo propios para reedificarlas...» Id., Caja 865.

22. «...porque a lo general de la nación y aumento de los pueblos conviene que no se mantengan reunidas en una mano muchas cosas y que entren en la circulación del comercio las que están fuera de él...». Ibidem.

23. Ya hemos señalado que también el de Astorga y el de Valencia de don Juan proceden a la venta de casas, el último una casa por valor de 7.400 reales, que son ingresados en la tesorería general dentro de la operaciones financieras ya analizadas de la Renta del Tabaco.

24. Cifra muy por debajo de las otras ciudades castellanas, como Burgos con un 16-17\% o Salamanca con un 27,9\% Álvarez DE PrADO, Alfredo, «Aportación al estudio de las haciendas concejiles castellanas, los propios y rentas de Burgos en el siglo XVIII», en la Ciudad de Burgos, 1985, p. 461. INFANTE, Javier, «La desamortización de las casas de propios a finales del siglo XVIII en la ciudad de Salamanca», en Desamortización y Hacienda Publica..., Madrid, 1986, p. 325.

25. LORENZANA FERNÁNDEZ, Antonio, «desamortización y transferencia ...», p. 181.

26. Los elegidos son don Fernando Sánchez Pertejo, arquitecto de la Real Academia de San Fernando, y don Francisco Rivas, maestro del obras públicas., A.H.P.L, Félix González de Mérida, Caja 865.

27. «... Se compone de cuarto bajo, principal y segundo bastante deteriorados...de unos 3.738 pies...». Ibidem.

28. A son de clarín y tambor. Ibidem.

29. Se hallaban presentes el corregidor, dos regidores perpetuos, el diputado de abastos y los procuradores síndico general y personero. Ibidem. 
cantidad que superaba el límite establecido por la real cédula de la cuarta parte de la valoración ${ }^{30}$. Finalmente, según la real cédula es el intendente el que da el visto bueno a la venta establecida, lo cual todavía se retrasa hasta agosto.

La cantidad obtenida por la venta de la casa se vuelve a imponer, tal como establece la real cédula, en la ya conocida Renta del Tabaco, al tres por ciento de interés. Por lo tanto, el ayuntamiento y la junta de propios obtienen un pequeño interés por esta propiedad, pero el efecto negativo es la pérdida de la misma, aunque como mal menor pasa a manos de una institución benéfica, como es el Hospital de San Antonio Abad.

Todavía creó más desasosiego, dada su relevancia, el denominado subsidio extraordinario de los 300 millones. Las urgencias de la Hacienda Real por hacer efectivo el nuevo subsidio determinaron que las sugerencias y propuestas del entonces Contador General de Propios y Arbitrios, don Antonio Noriega, no se tuvieran en cuenta y se siguió gravando a los ya extenuados fondos locales ${ }^{31}$. Así, como venía siendo tradicional la suma que correspondía pagar a cada ayuntamiento se calculaba en Castilla en función de las rentas provinciales y en Aragón a partir de los Catastros. Una vez fijada la cantidad los municipios tendría que proponer los arbitrios necesarios para cubrirla ${ }^{32}$ y «si no tuviesen arbitrios de que valerse procedan inmediatamente al repartimiento entre los vecinos» ${ }^{33}$. Es más, lo que no habían conseguido las continuas demandas de los intendentes desde 1760 se logró en estos momentos y así se permitió, por primera vez, a los delegados provinciales aprobar por sí mismos, sin necesidad de acudir al Consejo, un buen número de $\operatorname{arbitrios}^{34}$. En la ciudad de León, en la sesión del ayuntamiento del 14 de marzo de 1800, se hace referencia a esta Real Cédula del 12 de octubre de 1799, señalando que la cantidad que debe pagar la provincia es de 5.065.536 reales $^{35}$, los cuales deben ser repartidos entre los vecinos de acuerdo con

30. En la real cédula se establecía que no se admitirían las pujas que no llegasen a la cuarta parte de la tasación, teniendo que volverse a sacar de nuevo a subasta. Ibidem.

31. Cuando en 1799 se estudiaban establecer nuevos gravámenes sobre los fondos locales que permitiesen hacer frente al conflicto bélico contra Inglaterra, Antonio Noriega defendía ante Cayetano Soler, Secretario de Hacienda, una serie de soluciones que no afectasen de forma muy drástica a los fondos municipales, ya muy castigados por los gravámenes exigidos a lo largo de los años 90 . Así, Noriega era partidario que, durante el tiempo que se considerase oportuno, se destinase al pago de los 300 millones el 17 por 100 con el que estaban gravados hasta ese momento los fondos locales, ya que con ello se conseguirían en 1799 unos 12.750.000 reales. GARCíA GARCíA, Carmen, Las crisis de las haciendas..., pp. 262-264.

32. Ibidem, p. 264.

33. Real Orden del 10 de junio de 1800. Citada en la obra anterior, p. 264

34. Según C. García García, los arbitrios que directamente podían aprobar los intendentes eran los siguientes: sobrantes de propios y arbitrios, préstamos de personas pudientes, comunidades o fondos públicos de otros pueblos si ésos no lo necesitaban para cubrir la parte del subsidio que les correspondía, y ventas de trigo del pósito, siempre que no se enajenase la totalidad de su fondo. Al Consejo continuaban reservados la aprobación de los impuestos sobre abastos, ventas de fincas pertenecientes a propios o comunes, rompimiento de dehesas o baldíos y la facultad para cerrar tierras de particulares. Ibidem, p.264.

35. Cantidad superior a la de la provincia de Valladolid, que le correspondieron 4.117.353 reales. Ibidem, p. 267. 
sus profesiones y ganancias ${ }^{36}$. Lógicamente este sistema recaudatorio implicaba un novedoso ataque a los patrimonios de los sectores sociales privilegiados. De ahí, que en las sesiones posteriores del regimiento municipal se adopten nuevas soluciones y propuestas de carácter más tradicional. Así, en la sesión de la corporación local de finales de agosto, el día 29, el intendente y regidor don Jacinto Lorenzana, aclara que, tras resolver dudas respecto al subsidio extraordinario de los 300 millones, a la ciudad leonesa le corresponden pagar 540.019 reales $^{37}$. Y más tarde en la del 2 de septiembre, tras manifestar la queja por la alta cantidad que les había correspondido, la cual consideraban ya no se ajustaba a la realidad económica de la capital leonesa ${ }^{38}$, se hace una propuesta para conseguir el dinero requerido que contiene seis puntos: primero, que se cojan 54.466 reales que sobraron de las cuentas de propios y arbitrios del año anterior, 1799. Segundo, ante la imposibilidad por motivos de necesidad alimenticia de poder vender las 15.139 fanegas existentes en el pósito, éste podría ceder tres casas de reciente construcción localizadas en plena plaza mayor para su venta. Actualmente la renta que se obtiene de ellas es tan sólo de 3.000 reales y podrían sacarse 140.000 reales. Tercero, se pueden vender las maderas del común de vecinos existentes en el parque, las cuales valdrían entre 30.000 y 40.000 reales. Cuarto, sacar a la venta las dos praderas encharcadas tras las casas nuevas del rastro, de donde se obtendrían de 24.000 a 30.000 reales. Quinto, cargar cuatro cuartos más en azumbre de vino que se vendiese al por mayor y por menor en la ciudad este año y el próximo dos cuartos en azumbre. De este arbitrio se podrían obtener unos 80.000 reales. Y finalmente, se podrían programar para el próximo año cuatro corridas de toros y obtener las ganancias de los alquileres de los balcones de la plaza mayor. En definitiva, todas estas soluciones no llegaban a la cantidad que se debía pagar a la tesorería real y además incidían de forma muy negativa en los bienes del ayuntamiento y el común de vecinos de la ciudad leonesa. No obstante, apreciamos como, exceptuando el impuesto sobre el vino ${ }^{39}$, el resto de los productos alimenticios básicos, carne, pescado, legumbres, etc., no se tocaban, a diferencia de Valladolid $^{40}$. Quizás en esta decisión del ayuntamiento de no aumentar la fiscalidad indirecta de productos alimenticios básicos, exceptuando como hemos visto el vino, sea debida a que desde mediados del siglo XVIII las rentas provinciales del casco de la ciudad de León están encabezadas por el común de vecinos, tras desentenderse de ellas el regimiento, y son gestionadas por cuatro diputados, elegidos de forma indirecta por

36. Archivo Histórico Municipal de León (A.H. M.L.), Actas Municipales, Caja 79.

37. Ibidem.

38. Ya que las famosas ferias estaban en una situación, según el ayuntamiento, muy decadente. Ibidem.

39. El vino, sujeto a encabezamiento y obligación, es el producto de mayor carga fiscal y el que a mediados del siglo XVIII, 1757, aporta más cantidad a la Tesorería de las Rentas del Casco, con un 33,3\% del total. Ver BARTOLOMÉ BARTOLOMÉ, Juan Manuel, «De la administración particular a la gestión por el común ...».

40. En la ciudad vallisoletana tampoco el cuerpo capitular se mostró favorable a un reparto entre los vecinos y prefirió sacarlo de los arbitrios que gravaban el consumo: carne, pescado, cacao, vino, vinagre, licores y «bebidas compuestas». Y en Medina de Rioseco, también se permitieron arbitrios que recaían sobre el vino, legumbres y pescados. GARCÍA GARCÍA, Carmen, La crisis de las haciendas locales..., pp. 267-268. 
los vecinos a través de las parroquias ${ }^{41}$, y cualquier alteración debe contar con el visto bueno de los Directores de Rentas, los cuales vigilaban de forma muy celosa dichas rentas $^{42}$. De este modo, de todas las propuestas efectuadas por la corporación local, las que conocemos que se llevan a la práctica son los impuestos sobre la venta de vino, los cuales se suspenden en febrero de $1801^{43}$, y, sobre todo, la venta de las tres casas del pósito real, tras su solicitud y aprobación de la Diputación General de Rentas de la ciudad de León ${ }^{44}$ y del Consejo Real ${ }^{45}$. El proceso por el cual se realizó la venta de las mencionadas casas fue largo, ya que, en un primer momento, se sacaron a subasta las tres casas de forma conjunta con una valoración de 178.825 reales, la cual era superior a la que había estimado el ayuntamiento, tras la previa autorización del Consejo Real, la cual llegó en abril de $1802^{46}$. Pero dicha subasta conjunta no tuvo éxito y el procurador síndico general propuso que era mejor la subasta de cada una de ellas de forma independiente, para lo que era necesario volver a realizar la tasación de las mismas por los respectivos arquitectos ${ }^{47}$. Posteriormente, se fijaron los edictos para proceder a la nueva subasta ${ }^{48}$ y en julio de 1802 se adjudicaron en pública subasta dos de las tres casas a don José Simón Pérez y su hijo, don Juan Pérez ${ }^{49}$, familia que tenía arrendada y habitaba la primera casa, con la condición de que las cantidades fuesen pagadas dentro del corto plazo de tan sólo tres días ${ }^{50}$. No obstante, la tercera casa, la de mayor

41. Para una mayor información sobre este interesante y novedoso tema ver BARTOLOMÉ BARTOLOMÉ, Juan Manuel, «De la administración particular a la gestión por el común...».

42. En los años 1778 hubo un enfrentamiento con el intendente debido a problemas de elección de cargos y por un Real Despacho del Consejo de Hacienda se les dio la razón a los Directores de Rentas y en definitiva al común de vecinos. Ibidem.

43. Sesión del ayuntamiento del 27 de febrero. A.H.M.L., Actas Municipales, Caja 79.

44. La Diputación General se reúne en septiembre de 1800, presidida por intendente general y formada por los diputados del común de vecinos, y tras analizar los acuerdos del ayuntamiento, en concreto la venta de las casas de la plaza mayor cedidas al pósito y la enajenación de la alameda del parque, decide que se puedan vender las casas, pero no está de acuerdo con la alameda perteneciente al común. A.H.P.L., Joaquín Álvarez Losada, Caja 891.

45. Sorprende que a diferencia de Medina de Rioseco, donde también se propuso la venta de algunas de sus tierras de propios y comunes para cubrir los 432.872 reales que le habían correspondido, el Consejo autorizase a que se procediese a esta venta de casas del pósito en León. De nuevo, la dificultad de gravar los consumos podría explicar esta operación tan negativa para el común de vecinos. GARCÍA GARCÍA, Carmen, La crisis de las haciendas locales..., pp. 264-265.

46. La autorización se realizó con la condición de » ...admitir postores en ellas que cubran las dos terceras partes de los 178.825 reales de la tasación, con la calidad de que la calidad del remate o remates haya de pagarse en metálico...». A.H.P.L. Joaquín Álvarez Losada, Caja 891.

47. La misma se realizó en junio de 1802, tasando, dado el buen estado de las casas, una de ellas en 63.130 reales, la segunda en 48.780 y la tercera, que era la del Peso, en 66.915 reales. Ibidem.

48. En la ciudad de León en uno de los mástiles de su plaza mayor. También se fijaron en algunas localidades como Valderas, Astorga, Villamañán y La Bañeza. Ibidem.

49. Son los que habitan en renta una de las casas y en total pagaron 74.620 reales cuando su tasación había sido de 111.910 reales, un 33,4\% menos, cantidad que cubría las dos terceras partes requeridas. Ibidem.

50. Ibidem. 
valoración y destinada al Peso, no hubo quien hiciese postura en esta primera subasta y hubo que esperar a que fuese de nuevo subastada, en octubre de 1802, para que la comprase don Marcos González Unzue, en la cantidad de 44.615 reales, es decir cinco reales más de los exigidos ${ }^{51}$.

Finalmente, todo indica que en León ciudad, al igual que en el resto de la península, exceptuando las principales ciudades vallisoletanas ${ }^{52}$, no se cubrió todo el cupo asignado $^{53}$.

\section{LOS PROBLEMAS EN LA ENSEÑANZA: LA LLEGADA DE LAS ESCUELAS PÍAS}

A pesar de estos fuertes problemas económicos y fiscales, el ayuntamiento de la ciudad de León tendrá también tiempo para ocuparse de los derivados del mal estado de la enseñanza en los últimos años del siglo XVIII. Tras la expulsión de los jesuitas el estado de la enseñanza en la capital era, según los regidores, muy lamentable ${ }^{54}$. Sorprende que se haga referencia a la relevancia de los jesuitas en el terreno de la enseñanza básica de la ciudad, cuando las primeras letras no iban con sus sistema educador estereotipado de la Ratio Studiorum ${ }^{55}$. La tarea de la enseñanza, por lo tanto, en la ciudad de León en los últimos veinte años del siglo XVIII, era una responsabilidad que

51. Don Marcos González Unzue, es un comerciante leonés, que entre otras actividades se dedica al abastecimiento de vino de la capital. Ibidem.

52. Sobre los problemas que planteó en Segovia la mencionada contribución véase GARCía SANZ, Ángel, Desarrollo y crisis ..., Madrid, 1986, pp.422-428. En cambio en las ciudades vallisoletanas si se cubrieron los cupos asignados. GARCÍA GARCÍA, Carmen, La crisis de las haciendas locales..., p. 268.

53. No se llegó a recaudar el total de los 300 millones y hasta el proceso revolucionario de 1808, las haciendas locales entregaron al Estado por la mencionada contribución 154.236.841 reales. Ibidem.

54. El objetivo de este trabajo no es el desarrollo de la importancia de la enseñanza de los jesuitas. No obstante, si podemos señalar a modo de síntesis que en las disposiciones desarrolladas en De Collegiis et Domibus fundandis de 1541-1544, se ponían los cimientos de lo que se iba después a regularizar en el capítulo IV de las Constituciones. Era el lento descubrimiento de una vocación docente. Desde las Constituciones se insistía mucho en la gratuidad de la enseñanza y existían colegios, que según lo establecido por sus fundadores y promotores, se podían dedicar exclusivamente a la enseñanza primaria o secundaria. Sin embargo, siempre tuvieron una clara vocación universitaria, pues Ignacio de Loyola y sus primeros compañeros eran en el momento de la fundación universitarios en la Sorbona parisina. BURRIEZA SÁNCHEZ, Javier, «Los ministerios de la Compañía», en Los Jesuitas en España y en el mundo hispánico (EGIDO, Teófanes, coord.), Madrid, 2.004, pp.108-113. En el siglo XVIII la educación y enseñanza de los jesuitas se había centrado en la gramática (como entonces se denominaba lo que después equivaldría, más o menos, a la secundaria, a la preuniversitaria, que incluía también la latinidad, la retórica). EGIDO, Teófanes, «El siglo XVIII: el poder de la extinción», en Los Jesuitas en España y en el mundo hispánico..., p. 227.

55. Según EGIDO, Teófanes, los estudiantes pobres y los modestos, que no estaban para estudiar sino para trabajar en la agricultura o en los gremios iban por otros derroteros, y los maestros de gramática o las fundaciones nunca pudieron competir con los jesuitas. Además, los jesuitas penetraron en la universidad a través de la gramática monopolizando las facultades menores de artes, es decir, la de Filosofía y Letras EGIDO, Teófanes, Los jesuitas en España..., pp. 227-230. 
recaía en tan sólo cuatro maestros ${ }^{56}$, los cuales utilizaban el edificio y las instalaciones que ocupaban anteriormente la orden de San Ignacio de Loyola ${ }^{57}$. De los cuatro maestros: dos se dedicaban a enseñar a leer y escribir, otro a los rudimentos de la lengua latina y sintaxis y el cuarto a la versión y poética ${ }^{58}$. Las cantidades que se asignaban a estos maestros no están claras, ya que a veces se hace referencia a 12.218 reales y otras a que únicamente se les pagaba con el fondo de las temporalidades, lo cual daría una cantidad de tan sólo de 1.760 reales $^{59}$. Bien se tratase de una u otra cantidad, lo cierto es que dicha asignación no era suficiente ${ }^{60}$. Es más, la corporación local reconoce que es muy complicado resolver la situación ya que no «estando separadas las clases de silabar, leer, escribir y aritmética, es imposible que dos maestros atiendan al mecanismo de todo si el concurso es numeroso como se verifica en esta ciudad $\rangle^{61}$. Y finalmente, también hay un deterioro muy fuerte de la educación moral y religiosa. De ahí, que se proponga a los escolapios y a sus Escuelas Pías para que se establezcan en la ciudad, ya que «los estudios generales en una capital deben servirse por un cuerpo colegial que tenga el suficiente número de individuos hábiles y ejercitados para las clases principales y para las subdivisiones que haga precisas la mayor concurrencia de discípulos, pues sólo por este medio se lograría tener a mano sustitutos capaces para los casos de enfermedad...» ${ }^{62}$.

Las Escuelas Pías van a penetrar en el siglo XVIII por la antigua corona de Aragón y por Madrid ${ }^{63}$ y traen consigo la creación de un nuevo tipo de colegio más popular ${ }^{64}$. Esta función catequética de la enseñanza primaria queda de manifiesto en el protago-

56. En 1799 se señala que sólo había quedado un maestro, don Rafael de la Nava. A.H.P.L., Félix González Mérida, Caja 866.

57. El edifico del colegio de Ntra Sra. de los Ángeles, situado en la parroquial de Santa Marina. Ibidem.

58. Según las propias declaraciones de los regidores. Ibidem.

59. Así, se declara lo declara el propio ayuntamiento. Ibidem.

60. «para la subdivisión de las clases, indispensable en las grandes concurrencias, ni para establecer sustitutos de estos maestros en los casos de enfermedad y otras urgencias, quedando los niños abandonados y desorganizadas las escuelas». Ibidem.

61. Ibidem.

62. Ibidem.

63. EGIDO, Teófanes, «El siglo XVIII: el poder de la extinción...», p. 228.

64. Para FAubell ZaPATA, Vicente, el colegio de raíces universitarias medievales, es fruto de la transformación que hacen los jesuitas del complejo escolar medieval llamada escuelas en las que se enseña sobre todo a hablar y escribir en latín. La tendencia generalizada, ya analizada, del colegio jesuita se inclinaba, en un principio, a lo que hoy entendemos más como enseñanza media y en él seguía hablándose en latín. Este tipo de colegio cambia pronto de fisonomía porque las Escuelas Pías le cambian pronto su finalidad, su estructura y su tipo de alumnado. Desde fines del siglo XVI y principios del XVII se transforma en un complejo educativo dividido en clases en que además de la enseñanza media, tiene cabida lo que se entiende hoy como enseñanza primaria o básica y algo de enseñanza profesional. En él se habla en lengua vulgar. Su cambio de estructura interna tiene especialmente lugar en una nueva concepción de la enseñanza primaria. Y su alumnado es preferentemente pobre, popular y gratuito. Además, el colegio escolapio posee, según el autor mencionado, otra característica específica y diferencial con los jesuitas y es que es el único centro de trabajo y atención de los escolapios. 
nismo que la iglesia tuvo en la fundación de escuelas en el siglo XVIII ${ }^{65}$. Así los escolapios crearon veintiséis colegios en el curso del siglo XVIII y otros cinco en el primer tercio del siglo XIX, la mayoría en territorios de la antigua corona de Aragón y dejaron de satisfacer otras cuarenta demandas de otras localidades ${ }^{66}$. De las provincias actuales de Castilla y León sólo se creó la de León y las más cercanas a nivel geográfico las de Madrid (San Fernando y San Antón), Getafe y Villacarriedo en Cantabria ${ }^{67}$.

El proceso que llevó al establecimiento de las Escuelas Pías en la ciudad de León fue muy largo y complejo. Se inicia a finales de 1796, en octubre, mediante la reunión ya mencionada del ayuntamiento y el acuerdo tomado respecto a que se instalen y se hagan cargo de la enseñanza y educación los padres escolapios. Este proyecto fue comunicado al provincial de las Escuelas Pías, el cual encargó todos los trámites y la negociación con el ayuntamiento leonés a dos personas: al consultor provincial y vicerrector de las Escuelas Pías de Lavapiés de Madrid y a un ex lector de filosofía, teología y maestro de humanidades. Dichos comisionados estuvieron presentes, ya en el curso del año 1797, en la tasación y regulación de las obras que se tenían que efectuar en las casas de las escuelas, antiguo colegio de los jesuitas. Y tras tener el visto bueno de consejo capitular de las cantidades a pagar y obras a realizar, la junta provincial de los escolapios aceptó la fundación propuesta en junio de 1797. No obstante, todavía faltaba la licencia real, la cual fue concedida por la Real Cédula del 13 de enero de 1799 y el arreglo con el obispo de la diócesis, don Cayetano Antonio Cuadrillero. A pesar de tener todos los trámites cumplidos, sin embargo, todavía habrá que esperar a bien avanzado el año 1800 para que se establezcan definitivamente ${ }^{68}$.

Tal como ya hemos señalado, la ubicación e instalación de las Escuelas Pías y los padres escolapios se realizó en el edificio que había sido de los jesuitas y ahora ocupaban los maestros para la enseñanza y como lugar de residencia. Para ello, por una parte,

Este tipo de colegio es el que funda San José de Calasanz en los territorios españoles de Italia entre 1621 y 1645 y el que exportan los escolapios sardos y napolitanos a la metrópoli en 1677, cuando en otros territorios italianos y centroeuropeos ya lo había creado Calasanz desde 1597. FAUBELL ZAPATA, Vicente, Acción educativa de los escolapios en España (1733-1845), Madrid, 1987.

«Los colegios de escolapios y la atención educativa a los pobres», en Historia de la acción educadora de la iglesia en España. Tomo I. Edades Antigua, Media y Moderna, Madrid, 1995, p. 688.

65. También fue importante la labor de obispos, que abrieron escuelas gratuitas para niños pobres y de curas y canónigos que, en particular en la segunda mitad del siglo XVIII, asignan legados para pagar a maestros, según revela el caso de Galicia. SAAVEDRA, Pegerto y SOBRADO, Hortensio, El siglo de las luces. Cultura $y$ vida cotidiana, Madrid, 2007, pp. 112-113.

66. FAUBELl ZAPATA, Vicente, «Los colegios de escolapios y la atención educativa...», pp. 702-703.

67. Ibidem.

68. A pesar de que Vicente Faubell da como fecha la de 1799 y que en el acta municipal del 14 de marzo se hacer referencia a que ya se han invertido 7.274 reales en la manutención de siete religiosos y un operario; sin embargo, en el mismo acta el intendente apremia a que se paguen a los escolapios 12.000 reales para adecuar las oficinas conducentes al servicio de las escuelas y colegio de los fondos de los propios. Y en la sesión de mayo del mismo año se señala que es pronta la llegada de los religiosos. A.H.M.L. Actas Municipales, Caja 79. FAUBELL ZAPATA, Vicente, «Los colegios de escolapios y la atención educativa...», p. 703 . 
fue necesario realizar una serie de reformas previas en las dependencias que se iban a destinar a la casa del director y a los lugares de residencia y estudio de los alumnos, que son valoradas en 37.177 reales, los cuales pueden rebajarse 11.937 reales que es el coste de la madera que puede dar la ciudad ${ }^{69}$. Entre las reformas destaca la relevancia que se da a que exista una sala de estudio para los seminaristas con chimenea, dados los rigores de las temperaturas invernales leonesas, y crear una nueva galería de estudios ${ }^{70}$. Por otra parte, era necesario realizar obras para poder acomodar a los padres escolapios, calculadas en 21.697 reales, que rebajadas de nuevo las maderas que aportaba la ciudad quedaban en 17.360 reales $^{71}$.Y finalmente, también se estiman en unos 16.589 reales para equipar, amueblar el edificio y dotar los ajuares de los religiosos ${ }^{72}$

En definitiva, las obras y dotaciones necesarias para su establecimiento ascendían a la cantidad, rebajadas las maderas, de 59.189 reales, que se sacarían de los bienes comunales $^{73}$ en unos momentos muy delicados para las arcas y las propiedades municipales, tal como se ha analizado en las páginas anteriores.

Una vez asentados, el ayuntamiento les promete la cantidad anual de 12.218 reales para «su permanencia y manutención», los cuales eran, según algunos testimonios, los mismos que se asignaban a los maestros. Dicha cantidad procedía en su mayoría, el $67,6 \%$, de las rentas provinciales y el resto de la de los efectos de las temporalidades y de los propios de la ciudad ${ }^{74}$.

El número de religiosos que se estima serán convenientes para impartir dicha enseñanza es de diez ${ }^{75}$. También es interesante conocer el tipo de alumnos que pueden

69. Obra que se realizará según los materiales de este pueblo, con buenas puertas, ventanas, rejas y vidrieras y algunos cielos rasos. A.H.P.L., Félix González Mérida, Caja 866.

70. Según el arquitecto municipal fueron las siguientes: una vivienda para el director del colegio con sala, estudio y alcoba; sala de estudio para los seminaristas con su chimenea; una habitación para peinar; otra para baúles, capas y sombreros; deshacer todas las divisiones de los pisos principales de los maestros para dormitorio de los seminaristas; hacer en dicho piso un cuarto para uno o dos criados; un lugar común; una escalera falsa para la limpieza; deshacer la galería de los estudios y volverla a hacer de nuevo, de nueve pies de ancho, corriéndola por frente de los dormitorios. Ibidem.

71. En las casas que habitan los maestros de gramática se tenían que realizar las obras pertinentes para poder tener capilla, sacristía, refectorio, anterrefectorio, cocina, pasillos, divisiones de alcobas y lugar común, con blanqueo general y algunos rompimientos de puertas. Ibidem.

72. Ropas, vasos sagrados, menaje de cocina y despensa. Ibidem.

73. En realidad en la documentación disponible y analizada no queda claro si realmente se efectúan dichas obras y gastos previstos. Los escolapios las consideraban indispensables para establecerse, lo cual nos lleva a pensar en su realización, pero desconocemos si se ajustaron totalmente a lo diseñado o simplemente se efectuó un arreglo provisional, ya que en el ayuntamiento acuerda que «...se ejecuten los reparos absolutamente indispensables a fin de que pueda entregarse dicho edificio en el estado de regularidad y buen uno correspondiente a su destino, lo que sea y se entienda no excediendo la obra de tres mil reales sin incluir en ella las maderas necesarias». Ibidem.

74. En concreto, de las temporalidades 1.760 reales y de la junta de propios los 2.200 restantes. Ibidem.

75. Dos religiosos para primeras letras, tres para gramática, un supernumerario para las enfermedades, un rector, un director para el seminario y dos legos para la portería, sacristía, cocina y demás. Ahora bien, también se señala que«...si en los sucesivo aumentase demasiado el número de los niños y fuese nece- 
ser admitidos en dichas Escuelas Pías y el horario de enseñanza de las mismas. Así, respecto a lo primero, por un lado, se declara, que tendrán preferencia los hijos de los vecinos de la ciudad leonesa y de su jurisdicción; y, por otro, se establece que cada colegial pague tan sólo, de momento, seis reales diarios por su alimentación ${ }^{76}$. Incluso, es posible conocer las actividades de los alumnos y aproximarnos a su horario: cinco horas y media dedicadas cada día a los ejercicios literarios ${ }^{77}$. Previamente, antes de entrar en clase todos los alumnos tienen que asistir a una misa conjunta, el último cuarto de hora de clase se dedica a explicar la doctrina cristiana y una vez que terminan las clases se juntan en la iglesia para cantar las letanías y la Salve a la Virgen ${ }^{78}$. Los domingos y días de fiesta se dedicaran fundamentalmente a los actos de carácter religioso ${ }^{79}$. Y también deberán confesar una vez al mes ${ }^{80}$.

Por último, aunque resulta más complicado, podemos aproximarnos a su pedagogía $^{81}$, resumida al ayuntamiento por el apoderado de su congregación, el padre Fulgencio Gil del Rosario. Para él, el método de enseñanza comprende dos ramos:

sario subdividir alguna escuela pueda el provincial de dicha religión nombrar algún otro maestro para la mejor asistencia y desempeño de su sagrado ministerio...». Ibidem.

76. «..Teniendo consideración del estado actual de las cosas de primera necesidad y del precio subido de ellas, acordaron que pagase cada colegial seis reales diarios por sus alimentos que se reducen a su desayuno caliente por la mañana; al mediodía su sopa, cocido y principio; por la tarde su merienda de fruta de tiempo y por la noche su guisado y ensalada si la hay o en su lugar un postre...». Ibidem.

77. El horario en que empiezan los ejercicios literarios es en invierno por la mañana desde las ocho a las once y por la tarde desde las dos a las cuatro y media. Y en verano por la mañana desde las siete y media a las diez y media y por la tarde desde las dos y media hasta las cinco. Ibidem.

78. Faltaría la importante Oración continua, la cual la describe el Documento base de la pedagogía calasancia de la siguiente forma:» Todos los días desde el comienzo del la clase a la salida, se tiene la oración continua de nueve alumnos, con la asistencia de un sacerdote letrado, que instruye a los alumnos en el modo de hacer oración, y dura media hora; luego cambian otros nueve...a esta oración asisten, por orden sucesivo, todos los alumnos, comenzando por la primera clase hasta la última». FAUBELL ZAPATA, Vicente, «Los colegios de escolapios y la atención educativa...», p. 705.

79. Por la mañana tiene que asistir a los oratorios en los que se explica un punto de la doctrina cristiana, se lee un libro espiritual; a continuación los mayores recitan el Oficio Parvo de la Virgen y los pequeños el rosario y asisten a la Eucaristía. Por la tarde, deben ir a la explicación de la doctrina cristiana. A.H.P.L., Félix González Mérida, Caja 866.

80. El día anterior se les explica por parte del prefecto como tienen que hacer la confesión. Ibidem.

81. Según Vicente Faubell frente a la corriente metodológica de la Ratio Studiorum de los siglos XVI y XVII, Calasanz ni presenta un método ni pide que se siga uno determinado. Va más allá. En sus cálculos no existe, pues, un método definitivo. Pueden existir varios simultáneos y en las Escuela Pías se elegirá el que cumpla con las condiciones de sencillez, eficacia, brevedad y sea recomendado por los expertos. Es está pensando en la continua mejora metodológica, y fía, al menos en parte, la mejora educativa a la creatividad del propio maestro. No obstante, Calasanz articula un plan de estudios en nueve clases, que no significan nueve cursos, ya que pueden reducirse. De hecho los alumnos permanecen en su clase de acuerdo a su preparación personal, de manera, que previo examen, un alumno puede ser promovido al curso siguiente en cualquier día del año y especialmente dos veces durante el curso escolar. Tras la Escuela de la Señal de la Cruz (por edad y aprendizaje equivaldría Al parvulario de hoy), son cuatro clases de enseñanza primaria y cuatro de enseñanza media o secundaria. El documento en que se describe el plan se denomina como Documemtum princeps, Documento base o Breve relación, en la pedagogía 
uno político y otro moral. El político, consiste en enseñar a los niños desde los seis o siete años a leer y por medio de un examen que realiza el prefecto pueden pasar a la escuela de escribir. Más tarde pueden pasar a la escuela de gramática, la cual tendrá por lo menos tres preceptores ${ }^{82}$, sólo los que aprueben el examen. En definitiva, de forma sintética se refería a las tres principales clases en que al final se redujeron las cinco de la que podemos denominar escuela primaria: lectura (comprendía la de la Señal de la Cruz, el Salterio y la de Leer de corrido), escritura y ábaco, la cual hubo que anticiparla desde la clase de escritura y las clases de Gramática de la escuela media ${ }^{83}$. La redacción del texto escolar preocupa constantemente a los escolapios, que no suelen publicarlos sin una previa experimentación, hecha, a veces incluso, por todos los colegios de una misma demarcación. De ellos, son ejemplos ya clásicos los del P. Cayetano Ramo, publicado en 1759; las metodologías empleadas por los escolapios castellanos, recogidas por el P. Felipe Scío en su Método Uniforme de 1780 y en la enseñanza media destierran el latín eclesiástico y recuperan el latín clásico ${ }^{84}$. De este modo, no es de extrañar que en el informe del padre Fulgencio Gil del Rosario se mencione para las escuelas de León otro tipo de libros donde destaca la Novena de la Virgen de las Escuelas Pías, para facilitar en los comienzos el silabear con perfección y en la escuela de gramática el Arte de Nebrija y el catecismo de Astete ${ }^{85}$, por estar uno y otro establecido en este obispado ${ }^{86}$.

En definitiva, se trataba de implantar en León las Escuelas Pías según el modelo educativo y pedagógico ya previamente diseñado, pero con las adaptaciones señaladas y tan propias de los escolapios.

\section{CONCLUSIONES}

En los años del reinado de Carlos IV, sobre todo entre 1793 y 1803, la provincia y particularmente la ciudad de León, tiene que enfrentarse a dos graves problemas: por una parte, las fuertes exigencias fiscales de la tesorería real, provocadas por la relevante crisis de la hacienda, que afectan de forma negativa, como no podía ser menos, a los

calasancia y es al menos de 1604-05, aunque es probable que fuera ya del periodo 1597-1600. FAUBELL ZAPATA, Vicente, «Los colegios de escolapios y la atención educativa...», pp. 689-700.

82. Uno de rudimentos, otro de sintaxis y otro de propiedad latina que deberá enseñar retórica y poética. A.H.P.L., Félix González Mérida, Caja 866.

83. La Gramática comprendía cuatro clases. Para poder seguir con mayor detenimientos este aspecto ver FAUBELl ZAPATA, Vicente, «Los colegios de escolapios y la atención educativa...», pp. 697-699.

84. Ibidem, pp. 705-706.

85. Se refiere al catecismo tan popular escrito por el padre jesuita don Gaspar Astete a finales del siglo XVI. Después del finalizado el Concilio de Trento, en el que la Iglesia encargó a sus ministros la enseñanza resumida de las verdades fundamentales de la religión católica a los niños, elaborado en forma de diálogo, con el objetivo de hacer más fácil el aprendizaje de memoria del mismo. El Astete se utilizó en las escuelas del norte de España. RUIZ BERRIo, Julio, «Los manuales y los objetos escolares como instrumentos de reforma educativa en el reinado de Carlos IV», en La época de Carlos IV (1788-1808) (Edición de De Lorenzo Álvarez, Elena), Oviedo, 2009, p. 1023.

86. A.H.P.L., Félix González Mérida, Caja 866. 
vecinos leoneses y particularmente a sus bienes municipales, los cuales son enajenados, en concreto cuatro inmuebles urbanos, que pasan a propiedad particular, ante la imposibilidad de poder incrementar más los impuestos sobre el consumo de productos básicos. Además, los capitales de las obras pías con destino a la educación de los pobres, son también reorientados hacia censos estatales, teniendo como base la Renta del Tabaco, descapitalizándolas y perjudicando, en definitiva, su función asistencial y educativa. Y por otra parte, en la última década del siglo XVIII, tras la expulsión de los jesuitas, el estado de la enseñanza y de la educación de la juventud de la capital eran tan lamentable que el ayuntamiento propone para solucionarlo la llegada de las Escuelas Pías, las cuales tenían desde el siglo XVIII una mayor acogida. Su establecimiento requería no sólo salvar la burocracia y el correspondiente permiso real, sino que también exigía realizar un nuevo esfuerzo inversor, en años de máximas dificultades, para poder acondicionar los edificios y espacios destinados a los escolapios, los cuales saldrían de nuevo de los bienes municipales. No obstante, es de alabar la preocupación y el esfuerzo de los regidores y del procurador síndico general ${ }^{87}$, para buscar la solución del problema de la enseñanza y educativo, particularmente de la población más pobre, y más teniendo en cuenta las dificultades económicas del momento ${ }^{88}$. Así, las Escuelas Pías se establecen en la ciudad de León justo con la llegada del nuevo siglo XIX reemplazando al único maestro que existía en aquellos momentos de los cuatro que debían ejercer ${ }^{89}$. En fin, dos caras una negativa y otra positiva en relación al común de vecinos durante el reinado de Carlos IV en la capital leonesa.

87. Es cierto que los máximos impulsores fueron los regidores comisionados por el ayuntamiento don Manuel Castañón y don Claudio Quijada y Quiñones. Ibidem.

88. Hay que esperar hasta 1821 para que la Diputación Provincial de León acordase formular un Plan de Escuelas, en todos los pueblos, produciéndose un avance muy significativo en el campo de la instrucción pública. Celada Perandones, Pablo, «La infraestructura de escuelas en la provincia de León (18001950)», en Tierras de León, V.. 35, Nº7-99, León, 1994-95, pp.151-180.

89. A principios de mayo de 1800 , don Rafael de Nava, el único maestro titular que existía de las escuelas públicas de primeras letras, expone que lleva ocho años ejerciendo el magisterio de leer y casi dos años sustituyendo la cátedra de escribir y contar. Y »como es pronta la llegada de los escolapios solicita la plaza de portero mayor del ayuntamiento, vacante por defunción, cuya dotación es de 2.750 reales anuales, 50 menos que la plaza que deja vacante....». A pesar de esta solicitud el ayuntamiento nombró a otra persona, don Francisco Santón García. A.H.M.L., Actas Municipales, Caja 79. 
Cuadro 1. Capitales que toma el estado a censo sobre la renta del tabaco. Provincia de León (reales)

\begin{tabular}{|c|r|c|c|c|c|c|}
\hline Años & $\begin{array}{c}\text { Dinero } \\
\text { tomado a } \\
\text { censo }\end{array}$ & $*$ Indice & $\begin{array}{c}\text { Dinero } \\
\text { procedente } \\
\text { Obras Pías }\end{array}$ & \% & $\begin{array}{c}\text { Dinero procedente } \\
\text { Obras Pías dedicadas } \\
\text { a la enseñanza }\end{array}$ & $\%$ \\
\hline 1794 & 82.506 & 100 & 28.420 & 34,4 & 17.000 & 20,6 \\
\hline 1795 & 82.400 & 99,8 & - & - & - & - \\
\hline 1797 & 13.550 & 16,4 & 10.900 & 80,4 & - & - \\
\hline 1798 & $* * 13.780$ & 16,7 & 4.950 & 35,9 & 4.950 & 35,9 \\
\hline 1799 & $* * 155.601$ & 188,6 & - & - & - & - \\
\hline 1800 & 14.540 & 17,6 & 700 & 4,8 & - & - \\
\hline 1805 & 2.500 & 3 & 2.500 & 100 & - & - \\
\hline Totales & 364.877 & & 47.470 & 13 & 21.950 & 6 \\
\hline
\end{tabular}

Fuente: A.H.P.L. (Protocolos Notariales)

* Índice: 1794: 100. ** Años donde se toman también a censo las ventas efectuadas por los ayuntamientos de inmuebles urbanos debido al Real Decreto de 1798. 